\title{
The Development of Euclid Geometry's Teaching Materials Based on KKNI to Improve Students Cognition Analysis and Deductive Reasoning Abilities
}

\author{
Pinta Deniyanti Sampoerno ${ }^{1}$, Dwi Antari Wijayanti ${ }^{2 *}$, Qorry Meidianingsih ${ }^{3}$ \\ ${ }^{1,2,3}$ Universitas Negeri Jakarta \\ *dwi-antari@unj.ac.id
}

Received: November 2020; Accepted: December 2020; Published: January 2021

\begin{abstract}
This research aims to develop teaching materials that have been produced by the application of the learning model Means Ends Analysis in the form of Classroom Action Research. The development carried out in this study resulted in Euclid Geometry teaching materials based on KKNI to improve cognitive analytical skills and deductive reasoning of students of the Mathematics Education Study Program, State University of Jakarta. There were five steps carried out in developing this teaching material, including initial research, collecting data and information on needs, planning changes to teaching materials, developing early teaching materials, field trials, and revisions. The teaching material developed is suitable for use in Euclid's Geometry learning because it has passed the expert validation process. In addition, this teaching material has been tested on students who have been and are currently taking Euclid's Geometry courses. This concludes that Euclid Geometry teaching materials based on KKNI are feasible and can be used as a handbook for students in taking Euclid Geometry courses in the Mathematics Education Study Program of FMIPA UNJ.

Keywords: euclid's geometry, learning models, means-ends analysis, classroom action research.
\end{abstract}

How to Cite: Sampoerno, P.D., Wijayanti, D.A., \& Meidianingsih, Q. (2021). The Development of Euclid Geometry's Teaching Materials Based on KKNI to Improve Students Cognition Analysis and Deductive Reasoning Abilities. Journal of Medives: Journal of Mathematics Education IKIP Veteran Semarang, 5(1), 74-82. 


\section{PENDAHULUAN}

Mutu pendidikan menjadi hal utama yang harus terus ditingkatkan agar mampu secara sepenuhnya menjawab tantangan dunia, karena begitu pesatnya perkembangan di era globalisasi yang menuntut dunia pendidikan untuk terus berbenah diri. Menurut Wahyudi (2012) meningkatkan mutu pendidikan berarti meningkatkan komponen-komponen dan proses-proses pendidikan yang ada di dalamnya. Faktor keberhasilan terjadinya suatu proses pembelajaran di kelas yang paling utama adalah kemampuan gurunya dalam mentransfer ilmu dan pengetahuan yang dibutuhkan siswa. Hasil kerja guru akan lebih maksimal jika dalam penyampaian materi ditunjang oleh metode maupun media pembelajaran. Metode dan media yang digunakan guru diupayakan untuk menambah minat dan perhatian siswa terhadap materi yang diajarkan guru. serta motivasi siswa dalam belajar.

Pembelajaran matematika sangat membutuhkan penggunaan media pembelajaran karena konsep-konsep matematika yang abstrak membutuhkan visualisasi dalam memahami konsep matematika tersebut sehingga siswa mendapatkan informasi yang lebih kongkrit, jelas, dan terserap sempurna oleh siswa. Hal ini sejalan dengan pendapat Fowler (dalam Cindi, 2010) bahwa matematika adalah ilmu yang mempelajari tentang bilangan dan ruang yang bersifat abstrak sehingga untuk menunjang pembelajaran di samping pemilihan metode yang tepat juga perlu digunakan suatu media pembelajaran yang sangat berperan dalam membimbing abstraksi siswa.
Geometri merupakan cabang ilmu matematika yang membutuhkan visualisasi berupa gambar dalam pembelajarannya. Dalam pembelajaran geometri, pada umumnya untuk memperkenalkan konsep-konsep baru harus memperhatikan konsep-konsep sebelumnya yang sudah dipelajari. Mempelajari geometri sangat diperlukan dalam mengembangkan kemampuan kognisi siswa karena mereka dituntut untuk berpikir secara sistematis dan bernalar secara logis dengan pengetahuan yang dimiliki. Guru harus memanfaatkan bahan ajar sebagai alat bantu memvisualisasikan konsepkonsep geometri agar siswa mampu mencerna informasi-informasi yang diberikan dan diharapkan mampu menggunakan pengetahuan tersebut dalam kehidupan nyata.

Wijayanti (2018) melakukan penelitian kuantitatif dengan tujuan untuk melihat pengaruh metode Means Ends Analysis (MEA) dalam perkuliahan Geometri Euclid dan untuk meningkatkan kemampuan menalar deduktif. Hasil penelitian tersebut menunjukkan bahwa terdapat pengaruh yang signifikan atas metode MEA. Tahun 2019, Wijayanti melakukan penelitia lanjutan dengan menggunakan bahan ajar yang sama untuk sebuah penelitian kualitatif jenis Penelitian Tindakan Kelas (PTK), yang mempunyai tujuan untuk lebih menyakinkan bahwa penerapan metode pembelajaran MEA pada mata kuliah Geometri Euclid adalah metode pembelajaran yang tepat untuk menumbuhkembangkan kemampuan menalar deduktif mahasiswa. Hasil dari PTK tersebut membuat makin jelas bahwa metode pembelajaran MEA 
sangat mendukung mahasiswa untuk dapat menalar deduktif. Rangkaian berlogika hingga dimilikinya kemampuan menalar deduktif adalah melakukan kemampuan kognisi analisis, yang dilanjutkan dengan melakukan pembuktian sintesis dengan menggunakan pembuktian dua kolom. Dari catatan beberapa refleksi pada PTK sebelumnya terlihat bahwa kurang mendukungnya bahan ajar yang digunakan, karena belum adanya bagian yang sangat penting dari kemampuan mahasiswa yang harus diasah, yaitu bagian yang membahas tentang kemampuan kognisi analisis. Kemampuan analisa ini sangat diperlukan pada awal mahasiswa membahas soal dan kemudian akan membuktikannya. Bahan ajar akan lebih lengkap dan sempurna jika ditambahkan dengan bagian kognisi analisis.

Hal tersebut di atas menjadi dasar dan tujuan utama dari dibuatnya penelitian pengembangan ini. Hasil-hasil penelitian sebelumnya sudah dapat dijadikan sebagai sebagian dari analisis kebutuhan untuk penelitian pengembangan ini. Oleh karena itu, berdasarkan penelitian awal tersebut dan hasil wawancara dengan mahasiswa yang sudah mengambil mata kuliah Geometri Euclid, maka perlu dikembangkannya bahan ajar Geometri Euclid berbasis KKNI agar dapat meningkatkan kemampuan kognisi analisis dan menalar deduktif mahasiswa, khususnya di lingkungan program studi Pendidikan Matematika FMIPA UNJ.

\section{METODE PENELITIAN}

Metode yang digunakan dalam penelitian ini adalah metode penelitian pengembangan (Research and Development). Desain penelitian ini mengacu pada lima langkah utama yang dikemukakan oleh Tim Puslitjaknov yaitu melakukan analisis kebutuhan, mengembangkan produk, validasi ahli dan revisi produk, uji coba lapangan skala kecil dan revisi produk, serta uji coba lapangan skala besar dan revisi produk tahap akhir. Teknik pengumpulan data diperoleh dari uji ahli materi dan bahasa, uji coba lapangan skala kecil, uji coba lapangan skala besar, dan uji coba kelayakan bahan ajar kepada mahasiswa. Data diperoleh dengan menggunakan instrumen uji coba berupa angket atau kuesioner. Saat uji coba lapangan skala kecil dan skala besar, produk yang dihasilkan ditujukan kepada mahasiswa. Setelah melihat dan mempelajari produk, mahasiswa mengisi angket yang diberikan.

Pengujian konstruk pada penelitian ini menggunakan pendapat para ahli. Setelah instrumen dibuat, maka selanjutnya dikonsultasikan dengan ahli dimana mereka dimintai pendapatnya tentang instrumen yang telah disusun. Para ahli akan memeriksa kesesuaian instrumen tersebut dengan hal-hal yang perlu diperhatikan pada bahan ajar Geometri Euclid versi revisi.

\section{HASIL DAN PEMBAHASAN}

Pengembangan bahan ajar Geometri Euclid berbasis KKNI merupakan versi revisi berdasarkan hasil Penelitian Tindakan Kelas yang memerlukan tambahan bagian Kognisi Analisis. Untuk itu dilakukan penelitian pengembangan bahan ajar Geometri Euclid ini untuk menyusun kembali adanya 
Kognisi Analisis di setiap bab-bab yang ada. Langkah-langkah pengembangan bahan ajar dalam penelitian ini adalah sebagai berikut.

\section{Tahap Penelitian Awal}

Pada tahap ini, evaluasi terhadap hasil-hasil penelitian terdahulu dilakukan. Penelitian yang dilakukan oleh Wijayanti pada tahun 2019 adalah menerapkan model pembelajaran Means Ends Analysis (MEA) dalam bentuk Penelitian Tindakan Kelas. Penerapan model pembelajaran tersebut terbukti efektif dalam meningkatkan kemampuan menalar deduktif mahasiswa. Akan tetapi, dari hasil beberapa kali refleksi pada setiap akhir tiap siklus, masih terlihat kekurangmampuan mahasiswa dalam menyelesaikan soal Geometri Euclid, untuk itu selama melakukan PTK digali dan dicari penyebab kekurangmampuan mahasiswa dalam menyelesaikan soal Geometri Euclid dengan tepat, benar, dan sistematis. Berdasarkan hasil wawancara dosen dengan mahasiswa, diperoleh kesimpulan bahwa kognisi analisis yang terdapat pada salah satu bab, yaitu Bab 6, ternyata tidak cukup untuk membuat kemampuan tersebut digunakan pada bab-bab selanjutnya. Oleh karena itu, penelitian pengembangan ini bertujuan untuk melengkapi buku ajar yang sudah ada dengan menambahkan paparan tentang Kognisi Analisis di setiap bab, yaitu mulai dari Bab 6 sampai dengan Bab 15.

\section{Tahap Pengumpulan Data dan Informasi Kebutuhan}

Tahapan ini fokus dalam melakukan analisis kebutuhan mahasiswa.
Pengumpulan data dilakukan berdasarkan metode wawancara dengan subjek penelitiannya adalah mahasiswa yang telah mengambil mata kuliah Geometri Euclid pada tahun ajaran 2019/2020. Hasil wawancara menunjukkan bahwa masih terdapat beberapa poin penting yang dapat dijadikan sebagai dasar untuk pengembangan bahan ajar, di antaranya adalah sebagai berikut.

1) Cover kurang menarik dan isi tidak menampilkan gambar animasi pembelajaran.

2) Terdapat beberapa contoh soal yang salah atau kurang lengkap dalam tahapan penyelesaiannya.

3) Terdapat dalil atau postulat yang memerlukan penjelasan lebih detail.

4) Ukuran buku yang terlalu besar (ukuran A4), mahasiswa menyarankan untuk mengubah ukuran kertas menjadi B5.

5) Perlunya petunjuk awal bagi soal latihan yang sulit.

6) Perlunya dibuat bahan ajar versi $e$ book.

7) Desain isi bahan ajar lebih seperti buku ajar yang lebih professional, seperti buku Churchill atau Aljabs oleh Herstein dan lain-lain. Bentuk tulisan kompleks, padat tapi jelas, sehingga membuat pembaca tahu arahnya penulisan mau menuju ke mana.

\section{Tahap Perencanaan Perubahan Bahan Ajar}

Tahap perencanaan dimulai dengan memetakan hal apa saja yang sebaiknya ditambahkan dalam bahan ajar yang akan dibuat. Selain menambahkan paparan tentang kognisi analisis, 
hal penting lain yang perlu dilakukan adalah mengoreksi semua kesalahan penulisan, melengkapi jawaban yang kurang pada contoh-contoh soal, dan mengubah ukuran buku menjadi B5. Pemetaan materi lainnya adalah menganalisis kurikulum, mulai dari deskripsi mata kuliah, Capaian Pembelajaran Lulusan (CPL), dan Capaian Pembelajaran Mata Kuliah (CPMK), dan materi atau bahan kajian yang sudah ditetapkan oleh Program Studi Pendidikan Matematika FMIPA UNJ.

\section{Tahap Pengembangan Awal Bahan} Ajar

Pengembangan bahan ajar pada tahap awal adalah melakukan pendataan tentang adanya kesalahan penulisan pada keseluruhan isi buku serta kesalahan atau kekurangan pada jawaban contoh soal. Khusus untuk Bab 2-5 dapat langsung diperbaiki, tetapi pada Bab 1 diubah pengantar awal untuk disesuaikan dengan masa dibuatnya buku ajar revisi ini. Pada Bab 6-15 perbaikan tidak hanya pada kesalahan menulis, tetapi juga menambahkan paparan kognisi analisis pada setiap soal yang akan dibahas. Pada tahap awal ini juga dipikirkan untuk mencari gambar yang sesuai, untuk dijadikan gambar baru yang menarik pada tampilan cover buku. Tampilan cover yang baru memuat gambar bangun segitiga samasisi, jajargenjang dan lingkaran.

Salah satu hal yang perlu diperhatikan dalam tahapan ini adalah penulisan tentang konsep dasar Geometri Euclid itu sendiri, baik di dalam teori maupun di dalam contoh soal dan jawabannya serta dalam soal-soal latihan. Kekeliruan dalam penulisannya sebisa mungkin harus dihindari. Berikut adalah kesalahan yang ditemukan pada Bab 13. Kesalahan contoh soal ini berkenaan dengan penyebutan nama segitiga yang tidak mengikuti konsep dalam definisi "perkawanan dua poligon."

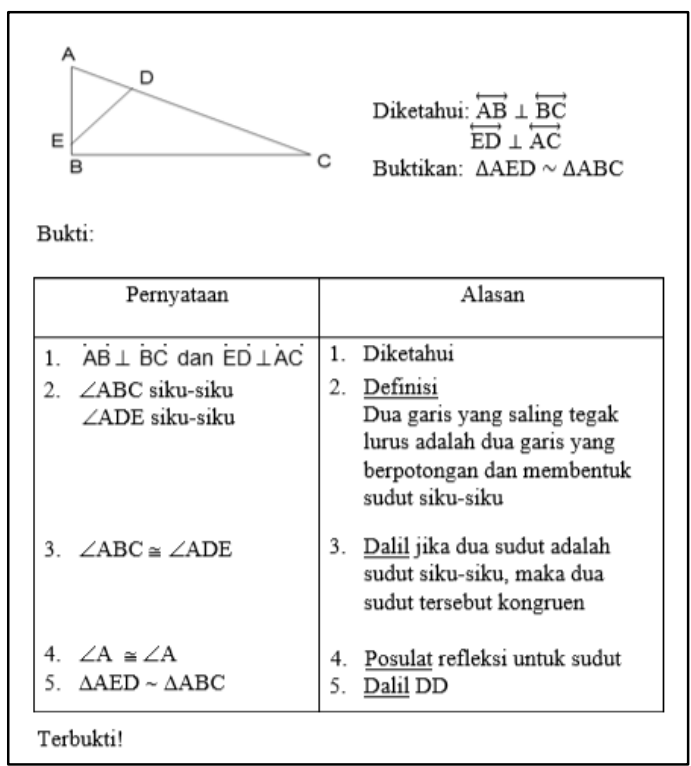

Gambar 1. Contoh Soal Dan Jawaban Bab 13

Halaman 116

Contoh soal dalam Gambar 1 pada awalnya seperti tidak ada kesalahan di dalamnya, tetapi setelah dicermati, kesalahan justru ada pada soal, sehingga pada pembuktian dua kolom ikut menjadi salah. Kesalahan ada pada bagian yang harus dibuktikan yaitu $\triangle \mathrm{AED} \sim \triangle \mathrm{ABC}$, dimana kesebangunan dua segitiga harus melihat perkawanan antara titik-titik sudutnya. Sangat jelas terlihat bahwa dari bagian yang diketahui sudut siku-siku ada pada $\angle \mathrm{ABC}$ dan $\angle \mathrm{EDA}$, sehingga permintaan pembuktian kesebanguan untuk $\triangle \mathrm{ABC}$ dan $\triangle$ AED adalah hal yang tidak mungkin. 
Masih dalam Bab 13 yaitu contoh soal kedua halaman 117 dimana kesalahan juga terdapat dalam soal yang diberikan, yang tidak mengikuti konsep dalam definisi "perkawanan dua poligon." Akan tetapi pada contoh kedua ini, juga terdapat kesalahan dalam langkah ke-7 dalam pernyataan sehingga perlu dibuat perbaikan dalam langkah tersebut.

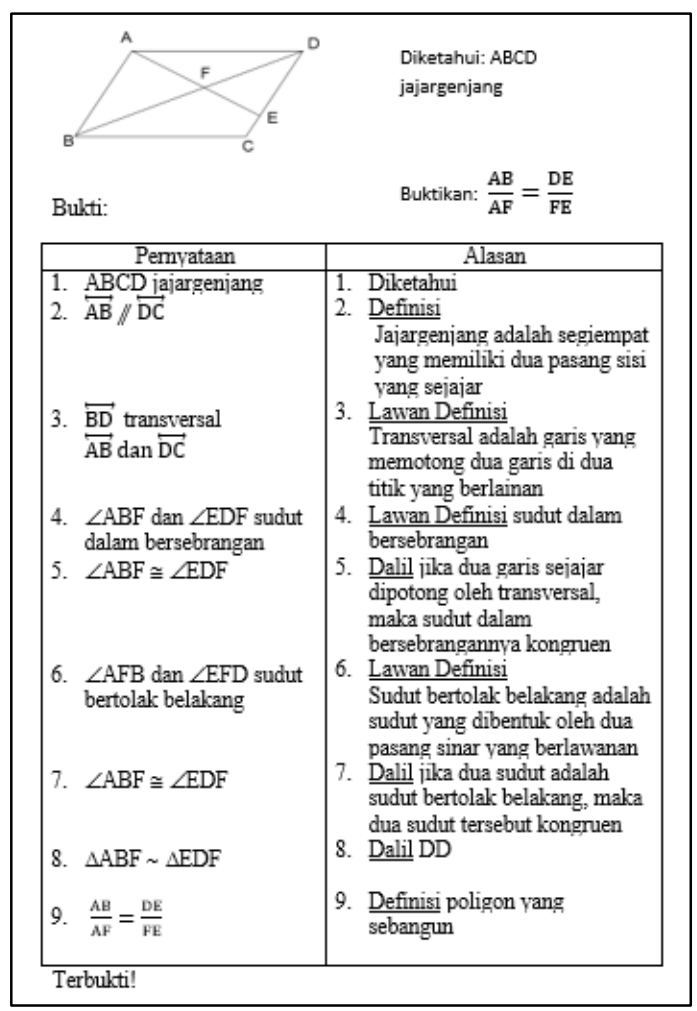

Gambar 2. Contoh Soal Dan Jawaban Bab 13 Halaman 117

Pada langkah ke-7 seharusnya yang kongruen adalah $\angle \mathrm{AFB}$ dan $\angle \mathrm{EFD}$, sesuai dengan pernyataan pada langkah ke-6. Pada bagian yang harus dibuktikan, jika harus memenuhi konsep pada definisi "perkawanan dua poligon" maka seharusnya persamaan $\frac{\mathrm{AB}}{\mathrm{AF}}=\frac{\mathrm{DE}}{\mathrm{FE}}$ diubah menjadi $\frac{\mathrm{AB}}{\mathrm{AF}}=\frac{\mathrm{ED}}{\mathrm{EF}}$.

\section{Uji Coba Lapangan dan Revisi}

Uji coba lapangan awal dilakukan kepada mahasiswa yang telah menempuh mata kuliah Geometri Euclid dan lulus di semester III, tahun ajaran 2019/2020. Pada tahap ini difokuskan untuk memperbaiki semua isi tulisan dan menyesuaikan ukuran buku sesuai hasil analisis kebutuhan.

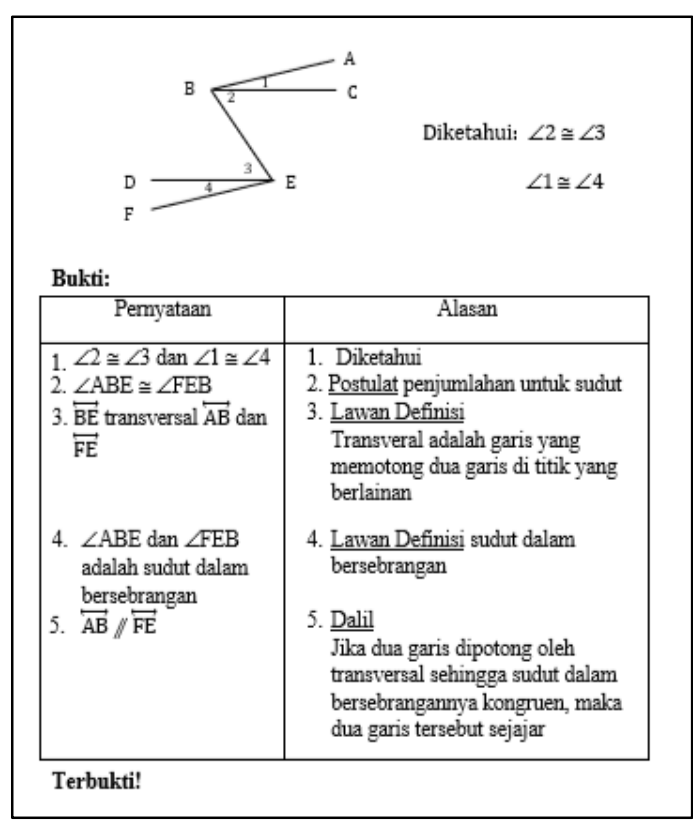

Gambar 3. Contoh Soal tang Diberikan Tanpa Kognisi Analisis

Gambar 3 merupakan salah satu contoh soal pada Bab 10. Pada soal diminta untuk membuktikan $\overleftrightarrow{\mathrm{AB}} / / \overleftrightarrow{\mathrm{FE}}$ dengan cara pembuktian dua kolom. Terlihat pada Gambar 3 tidak ada analisis apapun, tetapi langsung melakukan sintesa pada bukti dua kolom. Hal inilah yang akan diperbaiki pada revisi buku ajar Geometri Euclid. Gambar 4 menjukkan paparan perubahan pada contoh soal yang sama. 


\begin{tabular}{|c|c|}
\hline 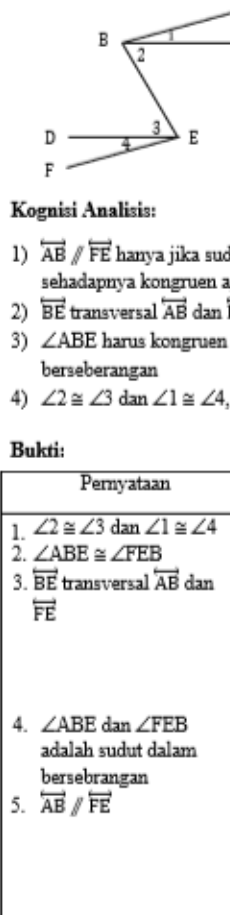 & $\begin{array}{l}\text { dalam berseberangan atau sudut } \\
\text { bila dipotong transversal. } \\
\text { karena memotong dua garis di titik berlainan } \\
\text { ngan } \angle F E B \text { karena merupakan sudut dalam } \\
\text { hingga } \angle A B E \cong \angle F E B \\
\text { Alasan } \\
\text { 1. Diketahui } \\
\text { 2. Postulat penjumlahan untuk sudut } \\
\text { 3. Lawan Definisi } \\
\text { Transveral adalah garis yang } \\
\text { memotong dua garis di titik yang } \\
\text { berlainan } \\
\text { 4. Lawan Definisi sudut dalam } \\
\text { bersebrangan } \\
\text { 5. Dalil } \\
\text { Jika dua garis dipotong oleh } \\
\text { transversal sehingga sudut dalam } \\
\text { bersebrangannya kongruen, maka dua } \\
\text { garis tersebut sejajar }\end{array}$ \\
\hline terbuikn: & \\
\hline
\end{tabular}

Gambar 4. Contoh Soal yang Diberikan Kognisi Analisis Hasil Kerja Mahasiswa yang Pernah Mengambil Mata Kuliah Geometri Euclid

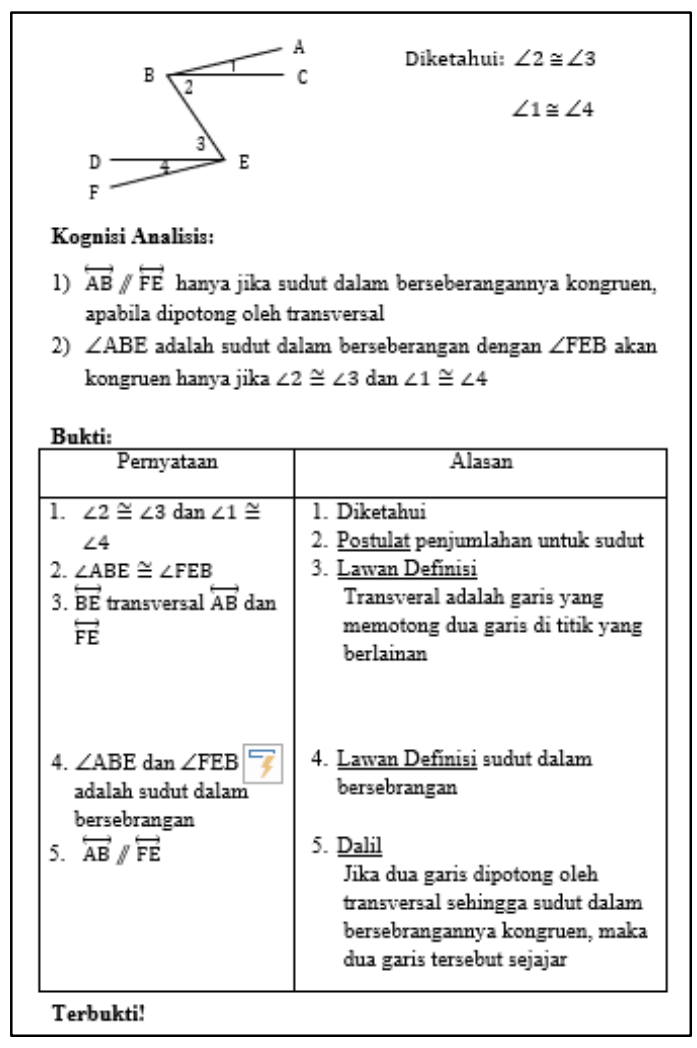

Gambar 5. Contoh Soal Dengan Kognisi Analisis yang Benar.
Contoh soal pada Gambar 4 sudah dilengkapi dengan kognisi analisis sebelum melakukan pembuktian dua kolom. Terlihat masih terdapat kesulitan mahasiswa dalam menyusun analisis karena pada saat menempuh mata kuliah Geometri Euclid kemampuan menalar secara kognisi analisis tidak terlalu ditekankan.

Melakukan kognisi analisis harus selalu dimulai dengan bagian yang akan dibuktikan, dengan logika "B hanya jika A" artinya B terjadi hanya jika A sudah terjadi. Pada Gambar 4 langkah pertama pada kognisi analisis yang dilakukan mahasiswa sudah benar yaitu dimulai dengan $\overleftrightarrow{\mathrm{AB}} / / \overleftrightarrow{\mathrm{FE}}$ terjadi hanya jika ada sudut dalam berseberangan atau sudut sehadap yang kongruen karena dipotong oleh transversal. Perhatikan soal yang ada, mungkinkah terdapat sudut sehadap yang dapat terjadi dari keadaan bangun seperti itu? Mahasiswa kurang cermat dalam mengamati kemungkinan yang terjadi. Langkah 2 yang ada, bukan analisis tetapi sintesis, karena menyatakan sesuatu yang sudah ada, dan akan digunakan. Bahkan pada langkah 3, terdapat penulisan yang terbalik secara logika kognisi analisis. Perhatikan pernyataan " $\angle \mathrm{ABE}$ harus kongruen dengan $\angle$ FEB karena merupakan sudut dalam berseberangan". Pahami jika $\angle \mathrm{ABE}$ kongruen $\angle \mathrm{FEB}$ bukan karena keduanya adalah sudut dalam berseberangan, melainkan karena keduanya sudah merupakan sudut dalam berseberangan. Oleh karena itu, harus dilihat apa yang ada pada bagian diketahui dari soal, yaitu yang dapat membuat kedua sudut tersebut menjadi kongruen. 
Jika dilihat pada soal, ternyata pada bagian yang diketahui terdapat $\angle 2$ $\cong \angle 3$ dan $\angle 1 \cong \angle 4$ yang artinya dengan menggunakan postulat penjumlahan akan didapat apa yang diperlukan, yaitu $\angle \mathrm{ABE}$ kongruen $\angle \mathrm{FEB}$. Logika yang harusnya terpikir oleh mahasiswa adalah bahwa kedua sudut tersebut harus sebagai dua sudut yang saling berseberangan dalam dan bukan sebagai dua sudut yang sehadap. Revisi dari soal tersebut, yaitu dengan kognisi analsisis yang benar disajikan pada Gambar 5.

Tabel 1. Komentar dan Saran Validator

\begin{tabular}{|c|c|c|}
\hline No. & Komentar & Saran \\
\hline 1 & $\begin{array}{l}\text { Masih terdapat gambar } \\
\text { yang ukurannya } \\
\text { kurang sesuai dengan } \\
\text { ukuran kertas B5. }\end{array}$ & $\begin{array}{l}\text { Gambar bangun } \\
\text { datar halaman } 60 \\
\text { masih terlalu } \\
\text { besar. }\end{array}$ \\
\hline 2 & $\begin{array}{l}\text { Usahakan semua soal } \\
\text { baik berupa gambar } \\
\text { dan soal dalam } \\
\text { equation dibuat dalam } \\
\text { gouping sehingga tidak } \\
\text { bergerak jika ada } \\
\text { penambahan materi } \\
\text { atau kalimat. }\end{array}$ & $\begin{array}{l}\text { Selain } \\
\text { menggunakan } \\
\text { grouping dapat } \\
\text { juga file final dati } \\
\text { bahan ajar di- } \\
\text { save dalam } \\
\text { bentuk pdf. }\end{array}$ \\
\hline 3 & $\begin{array}{l}\text { Konsistensi penulisan } \\
\text { definisi, postulat dan } \\
\text { dalil. Apakah selalu } \\
\text { dengan huruf kapital di } \\
\text { awal dan bold. }\end{array}$ & $\begin{array}{l}\text { Sebaiknya untuk } \\
\text { memudahkan } \\
\text { melihat dan } \\
\text { menemukan } \\
\text { definisi, postulat } \\
\text { dan dalil ditulis } \\
\text { tebal }\end{array}$ \\
\hline 4 & $\begin{array}{l}\text { Masih terdapat } \\
\text { pembuktian dua kolom } \\
\text { yang dengan } \\
\text { menggunakan tabel } \\
\text { terputus beda halaman. }\end{array}$ & $\begin{array}{l}\text { Usahakan demi } \\
\text { tampilan buku } \\
\text { yang baik, agar } \\
\text { tidak ada tabel } \\
\text { yang terputus } \\
\text { beda halaman. }\end{array}$ \\
\hline 5 & $\begin{array}{l}\text { Masih ditemukan } \\
\text { penjelasan suatu } \\
\text { definisi atau postulat } \\
\text { atau dalil, pada } \\
\text { halaman yang berbeda } \\
\text { pula. }\end{array}$ & $\begin{array}{l}\text { Diusahakan } \\
\text { tetap pada } \\
\text { halaman yang } \\
\text { sama sebuah } \\
\text { penjelasan dari } \\
\text { definsi, postulat } \\
\text { atau dalil. }\end{array}$ \\
\hline
\end{tabular}

Setelah setiap bab dilengkapi dengan kognisi analisis, maka tahapan selanjutnya adalah melakukan validasi ahli. Validasi ahli dilaksanakan dengan tujuan agar bahan ajar yang dibuat mendapat masukan dari validator yang ahli dalam bidangnya dan sebagai bukti bahwa bahan ajar yang dikembangkan telah layak untuk digunakan dalam penelitian. Tabel 1 menyajikan beberapa komentar dan temuan serta saran dari validator.

\section{PENUTUP}

Pengembangan yang dilakukan dalam penelitian ini menghasilkan bahan ajar Geometri Euclid berbasis KKNI untuk meningkatkan kemampuan kognisi analisis dan menalar deduktif mahasiswa di lingkungan Program Studi Pendidikan Matematika FMIPA Universitas Negeri Jakarta. Media pembelajaran yang dihasilkan ini akan digunakan pada perkuliahan Geometri Euclid sebagai salah satu buku pegangan mahasiswa. Terdapat lima tahapan yang dilakukan dalam mengembangkan bahan ajar ini, yaitu tahap penelitian awal, tahap pengumpulan data dan informasi kebutuhan, tahap perencanaan perubahan bahan ajar, tahap pengembangan awal bahan ajar, uji coba lapangan dan revisi. Bahan ajar yang dikembangkan ini telah layak untuk digunakan dalam perkuliahan Geometri Euclid. Hal ini terlihat dari indikator penilaian media pembelajaran yang telah divalidasi kepada ahli, yaitu dosen yang mengampu mata kuliah dalam rumpun mata kuliah Geometri di Program Studi Pendidikan Matematika FMIPA UNJ. Telah pula diujicobakan kepada mahasiswa yang telah menem- 
puh mata kuliah Geometri Euclid dan mahasiswa yang sedang menempuh mata kuliah tersebut.

Hal ini memberikan kesimpulan bahwa bahan ajar Geometri Euclid berbasis KKNI ini layak dan dapat digunakan sebagai salah satu buku pegangan mahasiswa dalam menempuh mata kuliah Geometri Euclid di Program Studi Pendidikan Matematika FMIPA UNJ. Pengembangan bahan ajar ini juga diharapkan dapat meningkatkan kemampuan kognisi analisis dan menalar deduktif mahasiswa yang merupakan kemampuan menganalisis suatu masalah dan menyelesaikannya dalam bentuk sintesa. Kemampuan ini sangat dibutuhkan mahasiswa matematika sehingga perlu dikembangkan agar memberikan landasan kepada mahasiswa untuk dapat berpikir dan bernalar secara sistematis dan logis.

\section{DAFTAR PUSTAKA}

Cindi, Mora. 2010. "Upaya Meningkatkan Hasil Belajar Geometri Melalui Penerapan Model Pembelajaran Kooperatif Metode Jigsaw II dengan Media Audio Visual di SMA Dipenogoro I Jakarta." Skripsi. Jakarta: Universitas Negeri Jakarta.

Tim Puslitjaknov. 2008. Metode Penelitian dan Pengembangan. Jakarta: Pusat Penelitian Kebijakan dan Inovasi Pendidikan.

Wahyudi, Iman. 2012. Pengembangan Pendidikan: Strategi Inovatif dan Kreatif Dalam Mengelola Pendidikan Secara Komprehensif. Jakarta: Prestasi Pustaka.
Wijayanti, Dwi A. dan Pinta D.S. 2018. Pengaruh Penerapan Model Pembelajaran Means Ends Analysis (MEA) Terhadap Kemampuan Menalar Deduktif Mahasiswa Ditinjau dari Kemampuan Awal Representasi Matematis Mahasiswa Program Studi Pendidikan Matematika FMIPA UNJ.

Wijayanti, Dwi A. dan Pinta D.S. 2019. Penerapan Model Pembelajaran Means Ends Analysis (MEA) untuk Meningkatkan Kemampuan Menalar Deduktif Mahasiswa pada Mata Kuliah Geometri Euclid pada Program Studi Pendidikan Matematika FMIPA UNJ 